\title{
Food Security in Qatar during COVID-19 Pandemic
}

\section{Bello AS and Ben-Hamadou R*}

Department of Biological and Environmental Sciences, College of Arts and Sciences, Qatar University, Qatar

*Corresponding author: Radhouane Ben-Hamadou, Department of Biological and Environmental Sciences, College of Arts and Sciences, Qatar University, Doha, Qatar, Tel:

Short Communication

Volume 6 Issue 2

Received Date: February 07, 2021

Published Date: March 12, 2021

DOI: $10.23880 /$ fsnt-16000261 +97444036454; Email: benhamadou@qu.edu.qa

\section{Abstract}

The novel COVID-19 pandemic that affects global food production and accessibility is a great concern/risk towards different country's capacity to the attainment of stable and sustaining food security. Thus, Qatar's food security like every other country of the globe is under a threat because of the COVID-19 pandemic which has been so far well managed because of its robust policies, social structure and proactive measures. Before the pandemic, Qatar has strengthened its food security status through laudable fiscal policies that focus on the local production increment, diversifying the sources of food imports and edible items, and overseas agro-business to ensure stable food supply at affordable prices. Hence, this mini-review looks into the current state of food security in Qatar amidst the global COVID-19 pandemic to establish if the current trend will help ensure food availability and accessibility in the foreseeable future.

Keywords: Food Security; COVID-19; Food Production; + Supply chain; Qatar

\section{Introduction}

An outbreak of a novel coronavirus, the COVID-19 was first reported in December 2019 from the city of Wuhan, China [1]. In no time, the COVID-19 penetrated the almost entire globe sporadically and by March 2020 the World Health Organization WHO declared the virus as pandemic as it is prevalent in all countries of the world [2,3]. Concurrently to other countries in the region, Qatar reported the first COVID-19 case on 27 February 2020 [4,5]. The countries of the globe took similar measures to prevent the spread of the virus within and between other countries by imposing restrictions on movements, social distancing, wearing of face mask, shut down of businesses, border closing, the closure of education institutions, traveling bans, and remote working [4,6]. However, these measures in turn trigger a possible/probable negative impact on the global food systems because of the disruption on the food chain from the producer through transportation, distribution, and the final consumer. Interestingly, the impact of COVID-19 has been widely differed from country to country especially because of their proactive measures and epidemiological conditions. The situation is not different in Qatar but well managed based on the existing policies, adequate health systems, and proactive steps taken all of which have led to its success in ranking among the lowest case fatality rate in the world. The state of Qatar as a member of the Gulf Cooperation Council (GCC) is one of the biggest economies and less populous with an estimation of 2.7 million population largely dominated by an expatriate community [4]. Like any other countries globally, the impact of the COVID-19 pandemic is seriously felt particularly in the energy and aviation sector. The sharp fall in global oil prices and traveling restrictions have no doubt affected Qatar like other major players in the oil \& gas and aviation industry. The risk of food shortage and balanced nutrition deficiency arises because of different disruptions experiences since the pandemic necessitated a proactive measure to safe vulnerable people's food security, 
no doubt, like other countries of the world, COVID-19 has partially affected food security from the perspective of the supply chain of food imports and local production in Qatar (Figure 1). The United Nations (UN), Food and Agriculture Organization (FAO), and the World Bank have echoed persistently the negative impacts this pandemic will melt on the global food security and balanced nutritional pattern [7-
9]. Nevertheless, Qatar has been tactically and strategically addressing and handling this situation to ensure that food availability is sustained during and after the COVID-19 pandemic. Therefore, to alleviate the worries of the populace, Qatar took drastic measures to cushion any possible negative effects on the stable food availability in the country. These measures are detailed hereafter.

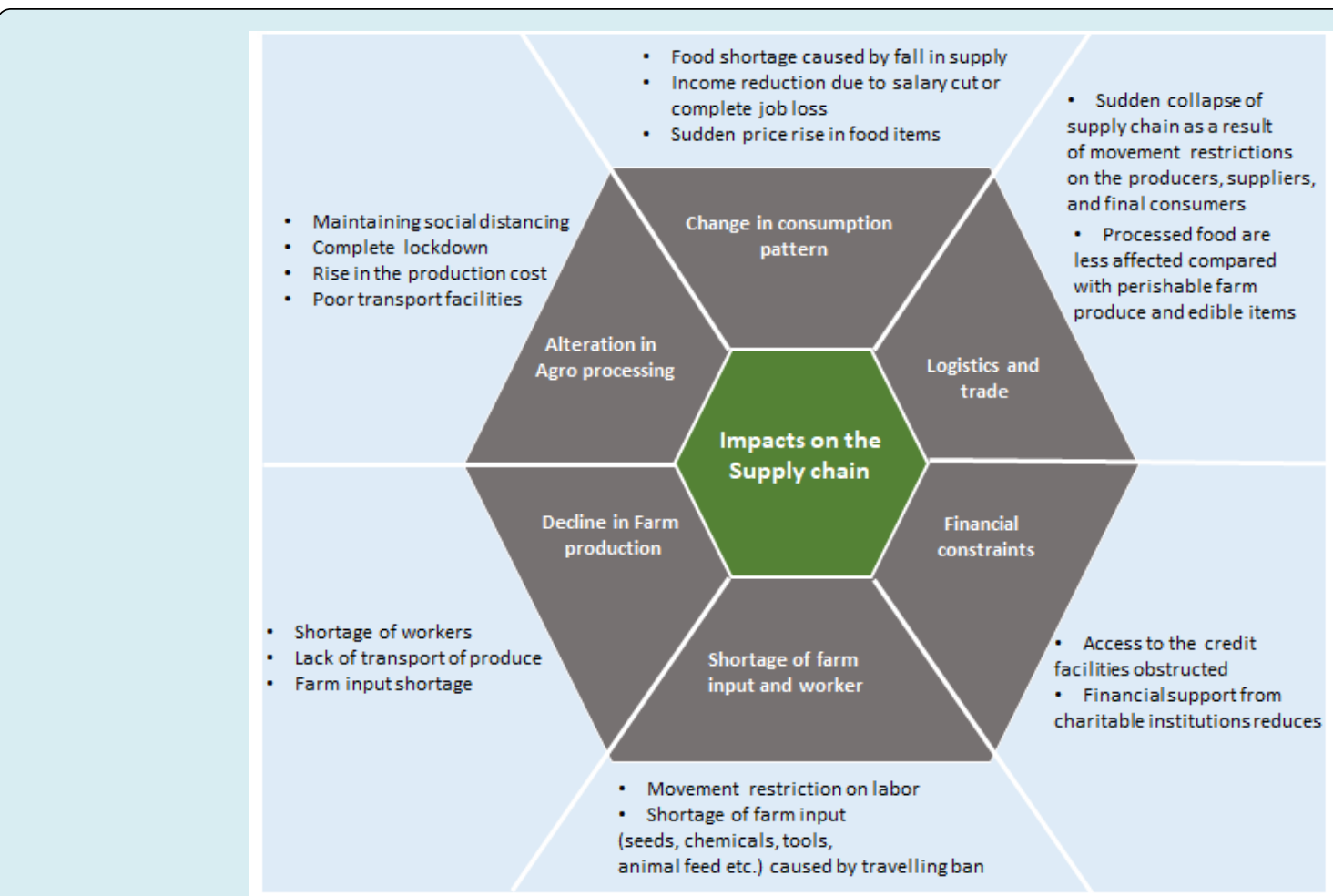

Figure 1: Adverse effect of COVID-19 on food security concerning supply chain of food imports and local production.

\section{Food Availability and Accessibility}

\section{Food Importation}

The Middle-eastern countries, and especially the GCC countries, are characterized by two pressing environmental issues like water scarcity and land degradation or desertification [10] which hinder productive agriculture/ crop production because of non-arable land, hence they mostly relied on the importation of various types of food ranging from fruits, cereals, vegetables, and animal products. Qatar, like other GCC countries, heavily relied on the importation of food and other edible items to compensate limited local production. Despite the pandemic impacts on various activities, the country has not shifted from its normal legislation and policies on the importation of food and edible items through pre-existing supply chains. The food value chain remains partially strong thus the food is available in the entire different outlets viz. groceries, food marts, supermarkets, hypermarkets, and the wholesale market at a reasonable price. The free inlet of food and edible items augment the local supply because the air and sea transportation for food and edible items were not altered despite the initial spread of the pandemic or the temporary border closure. The accelerated processing of food and edible items at the point of entry and stability in the relevant tariffs ease the inflow and subsequent movement to the different warehouses and the popular wholesales market known to be the engine of the food distribution chain in Qatar.

\section{Financial Support and Stability}

The importation of food from other countries were further enhanced by strengthening the financial commitment of various financial institution through relaxing their lending requirements and that of existing financing instruments viz. loans, credits, and advances with a negligible interest rate and payment conditions to cushion the negative effect of the 
pandemic on the financial stands of importers. Interestingly, the importer of food and edible items enjoys easy access to financial lending to facilitate the inflow of food items from different countries resulting in uninterrupted food availability and stability during and through the pandemic. The food price fluctuation is minimal because the local production creates equilibrium in the force/interaction between food supply and demand. No doubt, several local farmers are beneficiary of multiple credit facilities, enjoyed policies that encourage deferments and extension of interest payments, and support was given to assist farmers to handle and manage their credit facilities and financial challenge to sustain continuous and production stability which truly minimized the impact of the pandemic on food availability. The policies will likely remain in effect/operation for as long as the situation persists in order not to disrupt the food supply value chain.

\section{Political Stability}

The political unrest that erupted between some GCC member countries viz. the Kingdom of Saudia Arabia, Bahrain, United Arab Emirates (UAE) and Egypt which led to a manageable threat on the food security was successfully handled by the proactive measures taken by the State of Qatar. Indeed these four countries placed a ban on movement of citizens, goods and services from and to the State of Qatar in May 2017 due to political disputes between them. Nonetheless, the recent settlement in the dispute by lifting off the blockade on Qatar by the four countries is expected to boost the importation of food products at a competitive price. It is expected that food and edible items importation from these countries that recently lifted off the ban on Qatar will increase food availability and diversity in the country, which will subsequently enhance the food security of the country. No doubt, the recent development will surely boost the movement of goods particularly agricultural products from these countries to augment the local food supply and further diversify sources of food imports of the country.

\section{Sustainable Technology}

The agricultural system in many countries of the arid region particularly Gulf Cooperation Council (GCC) which includes Qatar is known to heavily depend on irrigated farming because of their less fertile soil and poor rainfall to support natural farming [11]. Qatar has the robust policy that focuses and encourage the adoption and use of different innovation and sustainable technology as an alternative to enhanceagricultural productivity thatinturn ensure domestic self-sufficient in most crops it has a comparative advantage in producing [12]. Thus, Qatar like many other countries in this region concentrates on applying this sustainable technology as farming techniques to replace the conventional soil-based farming system. Such sustainable technologies include but are not limited to hydroponics, aquaponics, and aquaculture are in use to offset food supplies from importation $[11,13]$. The technologies are characterized by their sustainability and eco-friendly properties as they use less water and space to sustain crop production/cultivation throughout the yearround. There have concerted efforts to ensure continuous support on the use of sustainable agriculture to increase local food production before, during, and after the pandemic. Therefore, this existing policy aiming at ensuring Qatar's self-sufficiency in producing agricultural goods that can be produced comparatively is maintained which subsequently placed the country in a comfortable zone to absorb any food insecurity shock that could emanate from this pandemic.

\section{Social Structure and Charity}

There are directives from the Qatar government and institutions to support the entire populace from the effects of the COVID-19 pandemic. The Ministry of Administrative Development and Labour Affairs for example mandates the employer oflabours the payments of their salaryas at when due even if the affected worker is in quarantine or temporary stop of business activities. Also, no employer should terminate the employee's contract without following due process and with the timely payment of all his entitlements. To further cushion the effect of the pandemic, the working hours of the workers are requested to be reduced and maintaining a sizeable workforce at all times. Interestingly, charity organizations and corporate entities viz. Qatar Charity, Qatar Red Crescent, Al Meera, Qatar National Bank, Doha Bank, Qatar Airways, Qatar Foundation, Ministry of Public Health, Ooredoo, and Qatar Petroleum [14] are seen as the most supportive brands during this pandemic in Qatar. They responded swiftly to the COVID-19 pandemic by providing supports to the residents, expatriates, and vulnerable groups by ensuring the supplies of palliatives at designated locations. The well-designed and coordinated distribution mechanisms and logistics facilitate the uninterrupted and hassle-free distribution of food items. The services of embassies and mission houses of different countries were sorted to achieve this. However, among the charity organizations, Qatar Charity is considered to have exhibited a distinguished success for being ranked as the first in humanitarian during this trying period [14].

\section{Conclusion}

The impact of COVID-19 on food security in Qatar is viewed from the current scenario concerning food availability and accessibility based on few resources at our disposal. Interestingly, Qatar's food security was less threatened and affected by the COVID-19 pandemic when compared with other countries in the region. The country is performing well in ensuring food availability at affordable prices during 


\section{Food Science \& Nutrition Technology}

the crisis which is far from over. Sustainable technology viz. hydroponics, aquaculture, vertical farming, aquaponics, and several other related green technologies have assisted Qatar in boosting its local production particularly in vegetables, date fruits, and fishes in an eco-friendly way. Nonetheless, the local production has improved the food supply value chain by augmenting and diversifying the importation from the international markets. Also, Qatar's policy and legislation reform create balance accessibility to food items among the populace particularly the expatriates that constituted the larger proportion of its population and other vulnerable groups. Hence, the recent reforms in the labor law are yielding the gradual desired results of eliminating the imbalance that is characterized by the labor sector. In conclusion, we are of opinion that the country will continue strengthening its policies in the relation to consequences of COVID-19 to give a reliable framework to attending and addressing similar unforeseen circumstances of such magnitude in the future.

\section{Acknowledgments}

Authors would like to acknowledge the support received from Qatar University for the position of Graduate Assistantship (Adewale Surja) and the Graduate Student Grant (Students Grants Cycle 1-2020) as part of it was used to finance the logistics part of the work.

\section{Author contributions}

All authors listed have contributed directly to the design of the work, data collection, data analysis and interpretation, drafting the article, critical revision of the article and final approval of the version to be published.

\section{Conflict of interest statement}

The authors expressly declare that there is no conflict of interest nor financial interest.

\section{References}

1. Novel CPERE (2020) The epidemiological characteristics of an outbreak of 2019 novel coronavirus diseases (COVID-19) in China. Zhonghua Liu Xing Bing Xue Za Zhi 41(2): 145-151.

2. Alhusseini N, Alqahtani A (2020) COVID-19 pandemic's impact on eating habits in Saudi Arabia. Journal of Public
Health Research 9(3): 1868.

3. Sohrabi C, Alsafi Z, O'Neill N, Khan M, Kerwan A, et al. (2020) World Health Organization declares global emergency: A review of the 2019 novel coronavirus (COVID-19). International journal of surgery 76: 71-76.

4. Ben Hassen T, El Bilali H, Allahyari SM (2020) Impact of COVID-19 on Food Behavior and Consumption in Qatar. Sustainability 12(17): 6973.

5. FAO (2020) HLPE. Interim Issues Paper on the Impact of COVID-19 on Food Security and Nutrition (FSN) by the High-Level Panel of Experts on Food Security and nutrition (HLPE). Food and Agriculture Organization (FAO), Rome, Italy.

6. Maliszewska M, Mattoo A, Van Der Mensbrugghe D (2020) The potential impact of COVID-19 on GDP and trade: A preliminary assessment. World Bank Policy Research Working Paper (9211).

7. Erokhin V, Gao T (2020) Impacts of COVID-19 on trade and economic aspects of food security: Evidence from 45 developing countries. International journal of environmental research and public health 17(16): 5775.

8. WFP (2020) World Food Programme. COVID-19 Will Double Number of People Facing Food Crises Unless Swift Action Is Taken.

9. World Bank (2020) Brief: Food security and Covid-19.

10. Richer R (2008) Conservation in Qatar: impacts of increasing industrialization. CIRS Occasional Paper (2).

11. Bello AS, Ahmed T, Ben Hamadou R (2019) Hydroponics: Innovative option for growing crops in extreme environments-The case of the Arabian Peninsula (A Review). Open Access Journal of Agricultural Research $4(5)$.

12. QNFSP (2018) Qatar National Food Security Strategy 2018-2023. Food Security Department.

13. Abusin SA, Mandikiana BW (2020) Towards sustainable food production systems in Qatar: Assessment of the viability of aquaponics. Global Food Security 25: 100349.

14. TP (2020) The Peninsula. Qatarıs Daily Newspaper. 